\title{
THE VALUE OF ENERGY AND RESOURCES - TOWARDS AN EFFICIENT FUTURE STEELMAKING *
}

Alexander Fleischanderl ${ }^{1}$ Thomas Steinparzer ${ }^{2}$

\begin{abstract}
Steel market has become somehow unpredictable and requires quick adjustment in production conditions to survive in the harsh market environment. Steel production is not anymore driven by output records, but by efficient cost reduction measures to remain competitive under strongly varying production conditions. Energy efficient production and flexible raw material scenarios have become decisive factors to succeed and survive in our industry. Such scenarios have to be carefully investigated to be well prepared to adopt production steps continuously. The paper analyses various process opportunities to optimize energy and raw material consumption in the production route. Off-gas treatment systems have still a huge untapped potential to recover energy from the hot waste gases. This is valid for the EAF mini mills as well as for the integrated route. Various examples for waste heat recovery systems including resulting benefits are discussed for the EAF, agglomeration, blast furnace, direct reduction and BOF. New innovative bag-filter systems feature extremely low emission levels at lowest pressure loss and sound emission conditions. Also improved control and automation solutions support the operators to minimize the operation and maintenance costs of their off-gas system. Steelmaking by-products shall not be considered as residues, but as a valuable and cheap raw material source. The paper presents some show cases how to valorize slags as well as utilizing coke and iron oxide fines to increase productivity and minimize raw material cost. A new process for highly flexible converter steelmaking allowing for extraordinary high $\mathrm{HBI}$ and scrap rates above $50 \%$ and improved yield is discussed and evaluated
\end{abstract}

Keywords: Raw Material Flexibility; Effective By-Product Management; Energy Efficiency; waste heat recovery.

1 Dr., Technology Officer Up-stream, Vice President, PhD in process engineering, Primetals Technologies Austria GmbH, Linz

2 Dr., Head of Technology ECO Solutions, PhD in process engineering, Primetals Technologies Austria GmbH, Linz 


\section{INTRODUCTION}

Raw material and energy costs represent the majority of production cost. However, the raw material market has become unpredictable and highly volatile. Costs for iron ore, $\mathrm{DRI} / \mathrm{HBI}$, coal/coke and scrap are facing short- and mid-term up and downs, whereby regional situations have to be considered. For example scrap prices in China have recently substantially decreased as the first wave of scrap recycling started following the production boom 15 years ago. On the contrary hot metal costs are increasing due to the fact that all blast furnaces less than $450 \mathrm{~m}^{3}$ have to be idled and therefore hot metal amounts become limited. Thus the delta cost between hot metal and scraps are actually reported 500 to $800 \mathrm{RMB}$ per ton in favor of scrap. Usually these circumstances should promote the EAF mini mill route, but the energy grid is limited especially for clean power. Thus, many steel plants are actually investigating how the scrap rate in the converter process can be pushed to $30-50 \%$. The development on the energy markets is another issue that was not foreseeable. Analysts were forecasting ever increasing cost for crude oil, electric power, natural gas and carbon emission trading. The shale gas boom has taught us different things. Carbon based energy prices collapsed and electric power reached historic low cost levels in many regions all over the world. We have even arrived at the paradox situation that the specific value of steam and natural gas can be higher than that of co-generated electric power. This situation requires careful investigation for the best energy recovery process to be applied.

However, the described situations are mainly politically driven and might change quickly. To challenge such unpredictable market conditions modular, flexible solutions and innovations are required that allows adjustments in all directions.

\section{Raw Material Flexibility - The Jet Process}

The Jet Process comprises a bottom blowing converter with coal and lime injection combined with a hot blast lance. The coal injected via the converter bottom as well as the coal already dissolved in the hot metal is combusted in two steps: 1. combustion to $\mathrm{CO}$ in the bath; 2. post-combustion to $\mathrm{CO} 2$ outside the bath. A simplified picture of this process is given in Figure 1.
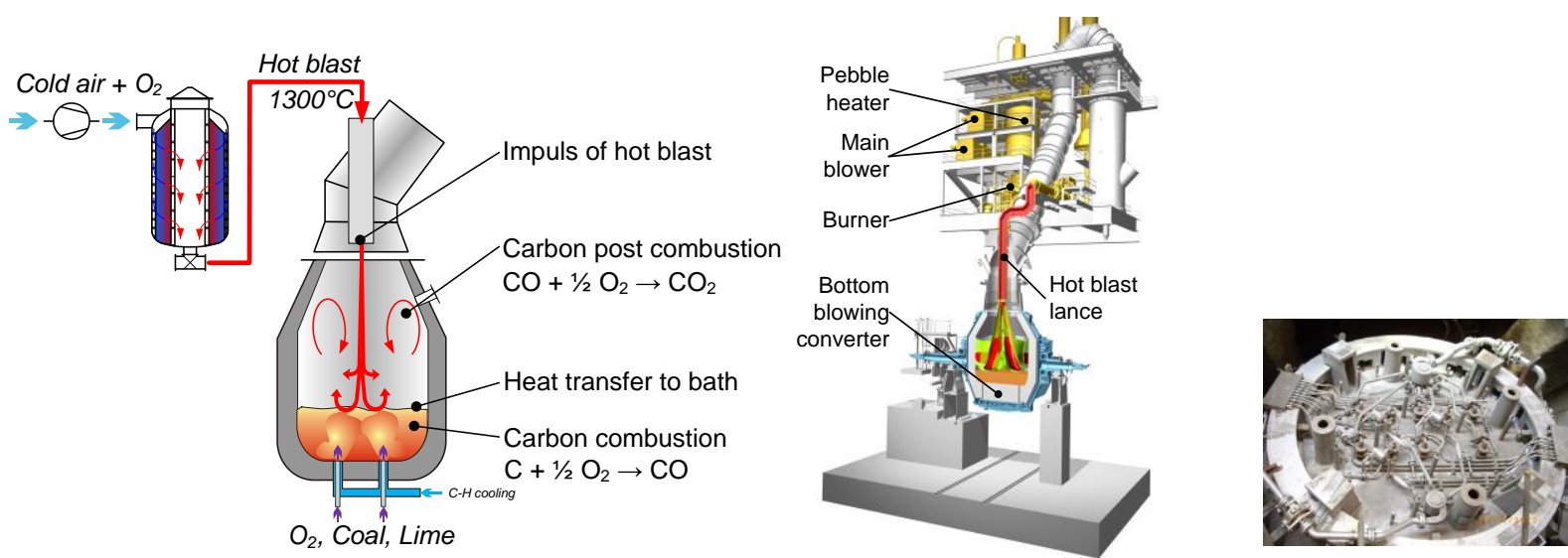

Figure 1: left: Jet Process principle - middle: Jet hot blast system - right: Jet converter bottom 
Two thirds of the chemical energy stored in the coal is released in the second step of the combustion. In order to use the coal efficient it is therefore, absolutely necessary to ensure that most of the $\mathrm{CO}$ is combusted to CO2. Beside a high PCD it is of importance, that the heat generated in the post combustion is transferred to the liquid bath, otherwise only the off gas would be heated up. The ratio of the total heat available that is transferred to the bath is described by the Heat Transfer Efficiency (HTE). In order to ensure high PCD and HTE an efficient mixing is required. This is achieved by a hot blast blown with a lance from top onto the bath. The hot blast consists of air which is enriched with oxygen to about $30 \%$ and heated up in a pebble heater to $1300^{\circ} \mathrm{C}$. The velocity of the hot blast at lance exit is slightly below to the velocity of sound which is around $700 \mathrm{~m} / \mathrm{s}$ at this temperature. Due to the high speed and the high volume of the hot blast, a jet with a very high penetration length is formed and a lot of surrounding media is sucked into the jet. This leads to an excellent mixing inside the converter, the $\mathrm{CO}$ coming from the bath is intensively mixed with the oxygen in the hot blast and combustion to $\mathrm{CO} 2$ takes place. Due to the high mixing energy of the jet, droplets from the slag and the steel path are generated. Because of the high surface to volume ratio such droplets are heated up very easily and contribute tremendous to the heat transfer from the hot gas to the liquid bath. State of the art simulation tools were used to optimize the lance tip and the lance position as well as PCD and HTE.

The intensive mixing with the hot blast ensures PCD up to $60 \%$ and HTE up to $90 \%$ leading to an off gas temperature that is in average about $150^{\circ} \mathrm{C}$ above the steel bath temperature. The total efficiency of coal used in the Jet Process for melting of solid charges is above $50 \%$. This is much higher than the efficiency that can be achieved if coal is used for electric power generation and melting is done in an EAF due to the losses during electrical power generation and transfer.

The pebble heater is operated in a two-step procedure. In the first step, during converter tapping and charging of the next heat, the pebble heater is reheated with natural gas for about 20 minutes. The energy is stored in the pebble bed and used during the blowing period - the second step - to heat up the oxygen enriched air for another 20 minutes. Consequently, for one converter only one pebble heater is required. The pebble heater is a very efficient, regenerative heat exchanger that uses pebbles to store the energy. Due to the high surface of the pebbles they have very high storage power and are ideally suited for short term heat storage. This in combination with the high storage density of the pebbles leads to very compact design of the pebble heater.

Oxygen for decarburization of the hot metal $(\mathrm{HM})$ is blown via tuyeres in the converter bottom. This tuyeres act like flame cutters and allow melting also large pieces of scrap fast and efficient. The bottom blowing leads to excellent mixing of the bath; hence all reactions are close to the equilibrium. This increases productivity and yield of the process, as less iron oxide is generated, tendency for slopping is low and total slag amount as well as iron content of the slag is low.

The Jet process is easily adapted to different scrap or HBI rates charged to the converter by adjusting of the amount of coal injected. Theoretically rates from $0 \%$ to $100 \%$ can be realized with the Jet Process. Up to $30 \%$ of scrap no coal injection is required. Comparison of Jet Process to EAF shows that for standard situations and average market prices the Jet Process will be economically more attractive for hot metal rates around and above 50\%, the EAF will be the better solution for hot metal rates below $50 \%$. 
A modular design is used for the entire converter - this allows adaption of the converter for BOF process as well as Jet Process. Most important in this respect are the converter bottom and the lance system with the attached piping and valve stands. This allows switching back operations from Jet Process to normal BOF operation if required.

Table 1: Main data for Jet Process and comparison to LD process and EAF

$\begin{array}{cccccc} & \text { LD } & \begin{array}{c}\text { Jet } \\ \text { Process }\end{array} & \text { Jet Process } & \text { EAF } & \text { EAF } \\ \text { Coal Injection } & \text { No } & \text { No } & \text { Yes } & \text { Yes } & \text { Yes } \\ \text { Scrap Rate } & 20 \% & 32 \% & 50 \% & 50 \% & 100 \% \\ \text { PCD } & 12 \% & 60 \% & 60 \% & - & - \\ \text { HTE } & - & 90 \% & 90 \% & - & - \\ \text { Yield } & 92 \% & 94 \% & 94 \% & 91 \% & 91 \% \\ \text { CO } & 1600 \mathrm{~kg} & 1250 \mathrm{~kg} & 1000 \mathrm{~kg} & 900 \mathrm{~kg} & 500 \mathrm{~kg} \\ \text { emissions } & \mathrm{CO}_{2} / \mathrm{t} & \mathrm{CO}_{2} / \mathrm{t} & \mathrm{CO}_{2} / \mathrm{t} & \mathrm{CO}_{2} / \mathrm{t} & \mathrm{CO}_{2} / \mathrm{t}\end{array}$

The first industrial application for the Jet process was installed at Posco Pohang, where Primetals supplied the core converter equipment. Just recently another installation for a $100 \mathrm{t}$ converter class was awarded to Primetals for a customer in China allowing for scrap rates up to 50\%. All intellectual property rights for the Jet process are with Primetals.

\section{Resource Saving - Effective By-Product Management}

\subsection{Slag Valorization - The DSG Process}

The largest amount of by-products is generated at the blast furnace, followed by converter operation, the EAF and secondary metallurgy. Three main challenges arise with the slag produced:

1. Utilization of the material generated in order to avoid landfilling and bringing the steel industry closer to the closed cycle industry targeting zero waste

2. Recovery of the latent heat of the slag which is one of the largest energy saving potentials still untapped

3. Efficient handling of the slag in order to minimize handling costs, logistic efforts, land consumption and environmental impacts like dust formation or water pollution.
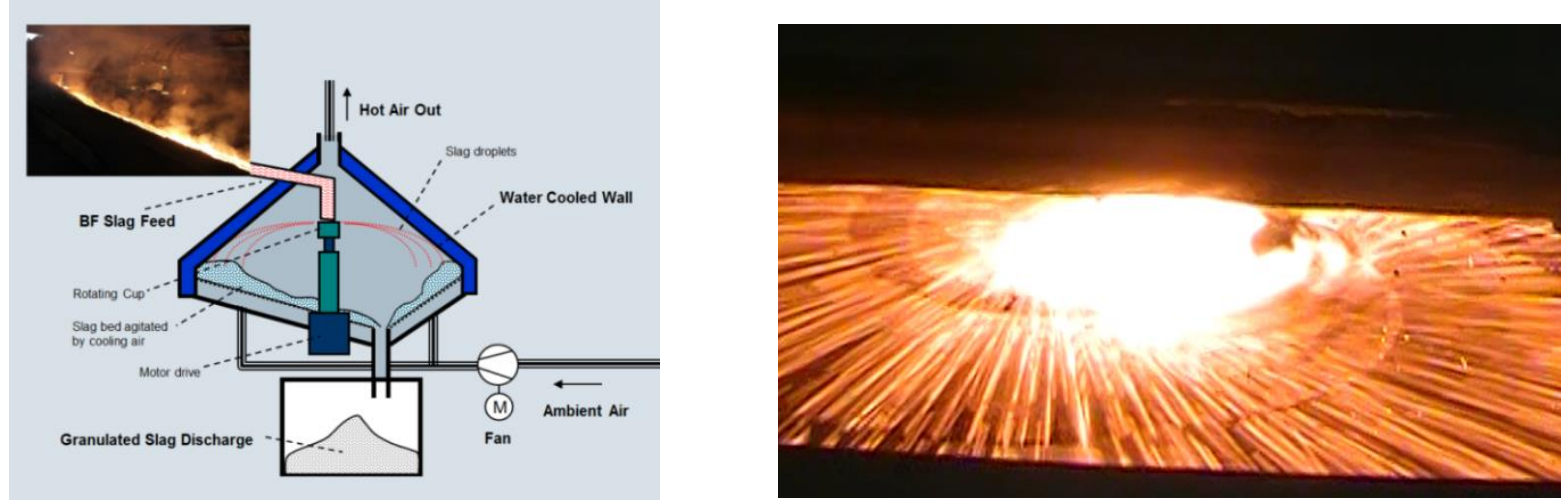
Figure 2: Dry Slag Granulation (DSG) Concept (left) and slag atomization at the rotating cup (right)

Each year approximately 400 million tons of blast furnace slag is produced worldwide. The slag, which has a tapping temperature of around $1,500^{\circ} \mathrm{C}$, is normally used as a substitute for cement clinker or as an aggregate material in road construction. The current state-of-the-art practice is to granulate molten blast furnace slag in wet-granulation plants using large volumes of water. However, up until now it has not been possible to utilize the remnant heat energy of the molten slag, which amounts to approximately $1.8 \mathrm{GJ}$ of energy per ton of slag.

Dry slag granulation is based on molten slag atomisation using a variable speed rotating cup or dish. The slag is delivered on to the centre of the cup from a slag runner via a vertical refractory lined pipe. The rotation of the cup forces the slag outwards to the cup lip where it is atomised. Simulation and calculation of the rotating cup gives as a result a suitable cup design with its main design parameter, the diameter of the cup and required rotational speed. The speed of the cup will be varied according to the current slag flow for a consistently product quality (grain size distribution...) and process stability.

An industrial size dry slag granulation prototype plant which will be capable of handling of about 60 ton per hour slag flow from a single tap hole is under commissioning. First heat is scheduled for June 2017. This step will improve process performance and evaluate detailed off gas parameter information for a subsequent heat recovery plant installation.
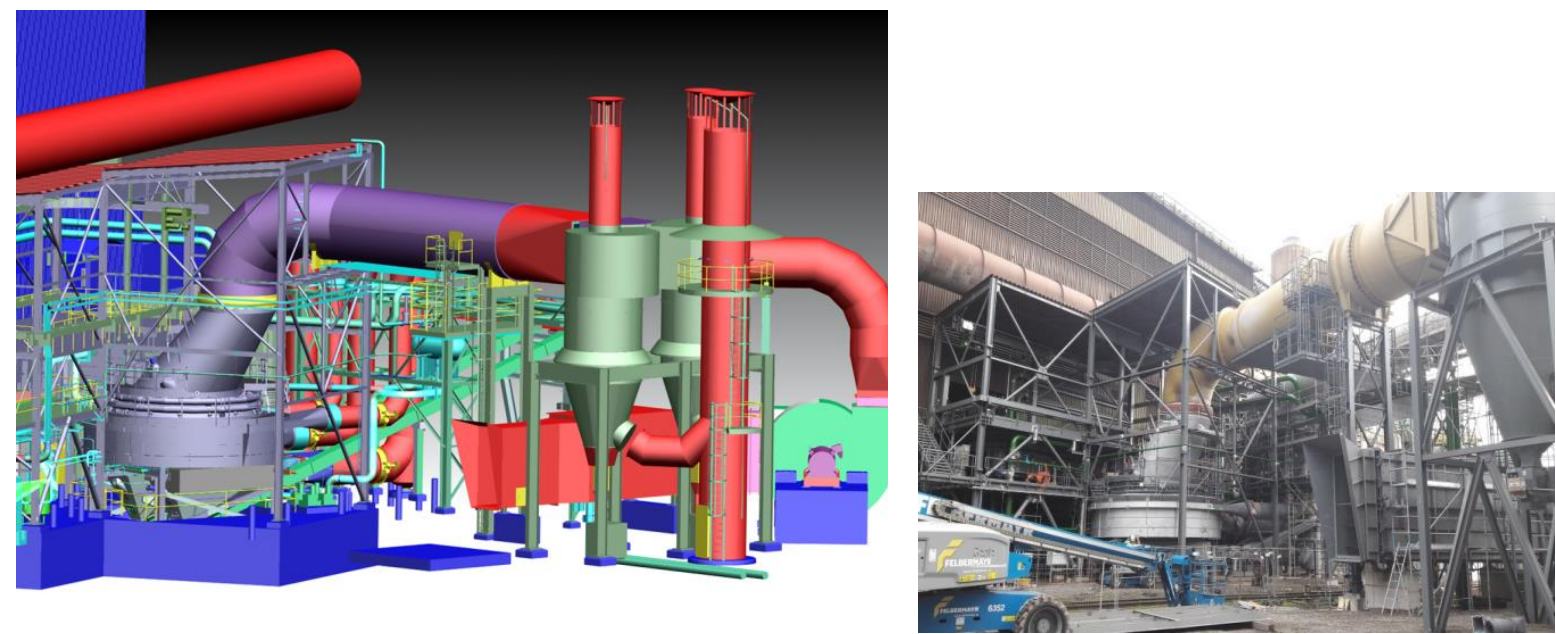

Figure 3: Model (left) and site view of prototype DSG installation during erection (right)

One of the main goals for the current dry slag granulation technology development was the recovery of the large thermal energy potential of the slag. By cooling the granulator with air the off gas can be used for driving different heat recovery applications. Several systems capable of utilising the energy in hot air delivered from the granulator have been considered. The major challenge is the intermittent availability of molten slag. For efficient heat recovery systems high temperatures of the off gas are required, so the aim is to produce off gas temperatures at $\sim 600^{\circ} \mathrm{C}$ at the industrial sized plants (previous research results already show promising temperatures). By tuning the cooling air distribution this could be increased significantly to around $650^{\circ} \mathrm{C}$. With the control of the cooling air amount in 
dependency on current slag flow the off gas temperature can be kept at a constant level for almost every load condition.

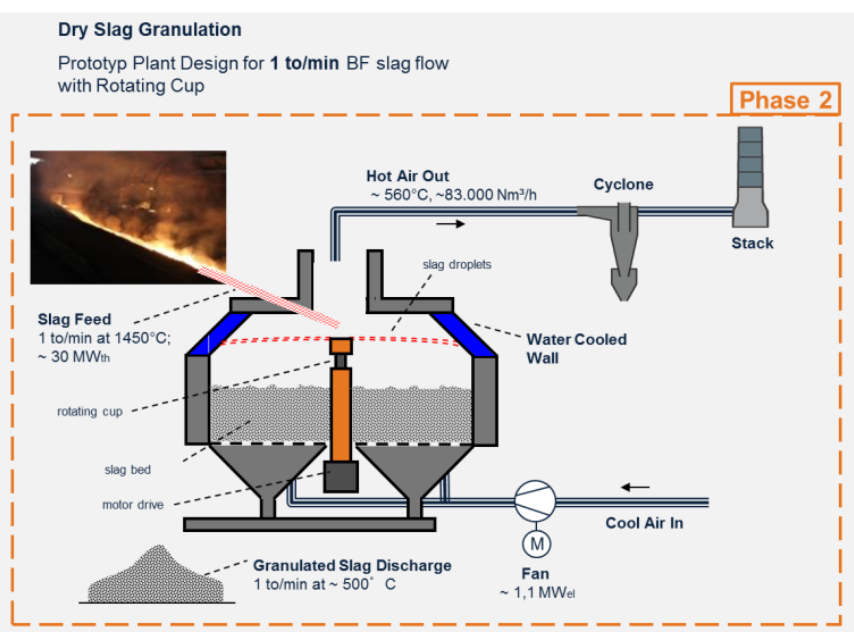

Figure 4: Process flow diagram of a dry slag granulation system with heat recovery system

Depending on the plant setup the energy can be used directly for preheating or heating purposes in the core process, or for the production of process steam and/or electricity. Generally the most common application for heat recovery is the production of process steam that can be used within the steelworks - feeding of steam in existing steelwork steam grid or replacement of fired steam boilers at steam consumers.

The granulator off gas will be guided into waste heat boiler(s) for steam production. Because of the high granulator off gas temperatures superheated steam of a high quality can be produced together with good thermal efficiency of the boiler. The boiler off gas can be partly recirculated to the granulator to create even higher total process energy efficiency. In Figure 9 the process flow diagram of a granulator and heat recovery system for superheated steam production is shown. The process parameters shown in this figure are exemplary for a slag flow of 1t/min which gives an output of approx. $29 \mathrm{t} / \mathrm{h}$ superheated steam. Converting this amount of produced steam in a steam turbine and generator means an electricity output potential of approximately 6,5 MWel (for $1 \mathrm{t} / \mathrm{min}$ slag flow).

\subsection{Oxides Fines Briquetting for Direct Reduction}

Governmental regulations around the world concerning environmental care are becoming more stringent, also including regulations and restrictions of landfilling and use of dust, sludge and slag generated in the iron and steelmaking process. With this scenario, by-products such as iron containing dust, sludge, oxide fines, mill scales and slag, become a valuable resource and recycling a profitable activity within a plant. Up to $10 \%$ in mass of the total steel output are dust, sludge and mill scale byproduct materials with an iron content ranging from $50 \%$ to $65 \%$ for fines.

The recycling concept for by-products generated in DRI plants has not yet been used until recently in an industrial scale. Based on the technology developed by Primetals the first plant of this kind was implemented by voestalpine Texas LLC in Corpus 
Christi. This plant produces briquettes from the by-product fines such as pellet fines and dust, DRI sludge, $\mathrm{HBI}$ fines and miscellaneous dusts generated in the plant, which can be recycled directly in the main DRI process in the same location, without necessity of long transportation and avoiding manual handling of the by-product fines. The major part of the by-product fines generated in the process are either transported directly from the collecting silos to the briquetting plant (oxide fines) or have a very short transport distance (DRI sludge).

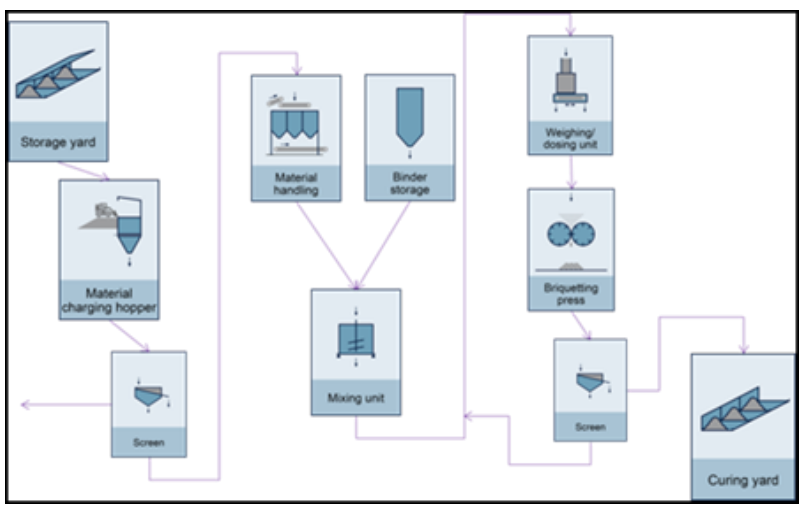

Figure 5: Process flow sheet

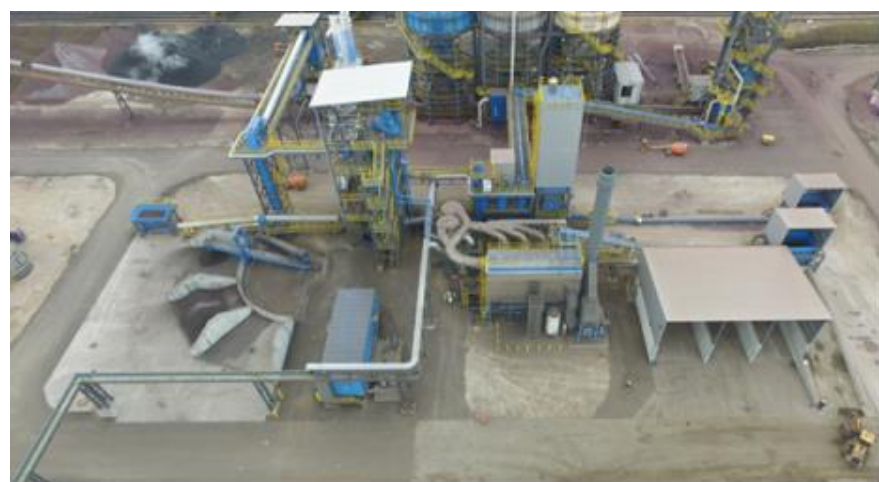

Figure 6: Briquetting plant site view Corpus Christi

Table 2: plant data of Fines Recycling Plant, voestalpine Texas LLC

Fines Recycling Plant

Feed material

Annual Capacity

Design Capacity

Binder system

Briquette size

Start Up pellet fines, sludge, HBI chips and fines, misc. dust

approx. 160.000

t/a

\begin{tabular}{|l|l}
24.6 & $\mathrm{t} / \mathrm{h}$ (briquettes)
\end{tabular}

inorganic binder

approx. 5

01.2017 $\mathrm{ccm}$

\section{Energy Efficiency}

In times of increasing awareness of energy consumption and tightening emission control, energy efficiency measures become more and more important for steel plant operators. For integrated iron and steel plants as well as for mini mills energy is one of the most important cost factors. Especially the vast amount of electric energy forces operators to improve the overall energy situation, in order to reduce the specific costs per ton steel and also to comply with legal requirements in terms of energy efficiency.

There are numerous opportunities along the iron- and steelmaking process for implementing energy efficiency technologies. Smaller improvements can be easily implemented without big actions. Such measures can be a modified plant operation, simple plant upgrades, or smaller automation packages. For a more decisive impact on the energy balance of a steel plant, bigger actions are required. With the installation of a waste heat recovery system a large amount of off gas energy can be 
utilized in form of steam and electricity, and hence reduce the specific energy costs of the plant.

\subsection{Novel EAF waste heat recovery systems for internal and external heat utilization}

Primetals Technologies has developed a novel solution for internal waste heat utilization within a mini mill based on an innovative waste heat recovery system. The solution is installed at an Italian steel plant, whereas the heat is used for on-site steam production. With the recently installed system, almost the entire steam demand of the plant shall be covered.

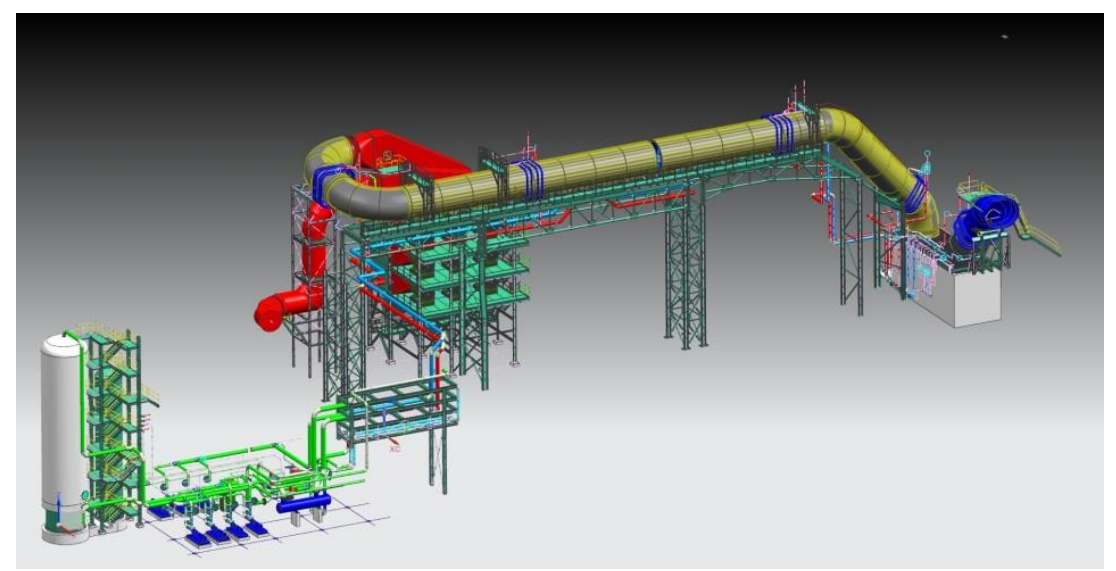

Figure 7: Waste heat recovery plant with steam generation

For the steel plant described above the recovered energy is used for steam generation. Thus, the hot water is fed to two different pickling lines at a distance of 1.5 and 0.5 kilometres. The large distance between heat recovery system and consumer is covered by long piping throughout the entire steel plant. This specific solution demonstrates that even long distances throughout the steel plant can be maintained.

Steam generators are installed, which are heated by the hot water from the waste heat recovery system. Thus, feed water is fed to the steam generator and is evaporated. In parallel, hot water is cooled down by transferring heat to the water/steam side. The cooled water is fed back to the heat recovery system. The produced steam is enough to substitute the existing gas fired boilers.

Furthermore a waste heat recovery system for external waste heat utilization was installed and successfully commissioned in 2016 at a steel plant in Sweden. The system is generating hot water, which is used for district heating of the nearby city.

Hot water is used for district heating applications. Therefore the recovered energy from the hot water system is transferred to the district heating network via a heat exchanger. A buffer tank is used to compensate the fluctuations of the hot water production and to provide a continuous water supply to the district heating system. From the heat recovery system, hot water is fed to the district heating network via long pipelines.

District heating is an interesting option for steel plants which are situated close to a city where a district heating network is already installed. Since the supplied heat from the mini mill is typically low compared to the heat demand of larger cities, steel plants can provide the heat over the whole season and not only during winter times to 
provide the base load for hot water consumers. Furthermore, this utilization concept helps steel plant operators to strengthen their green reputation.

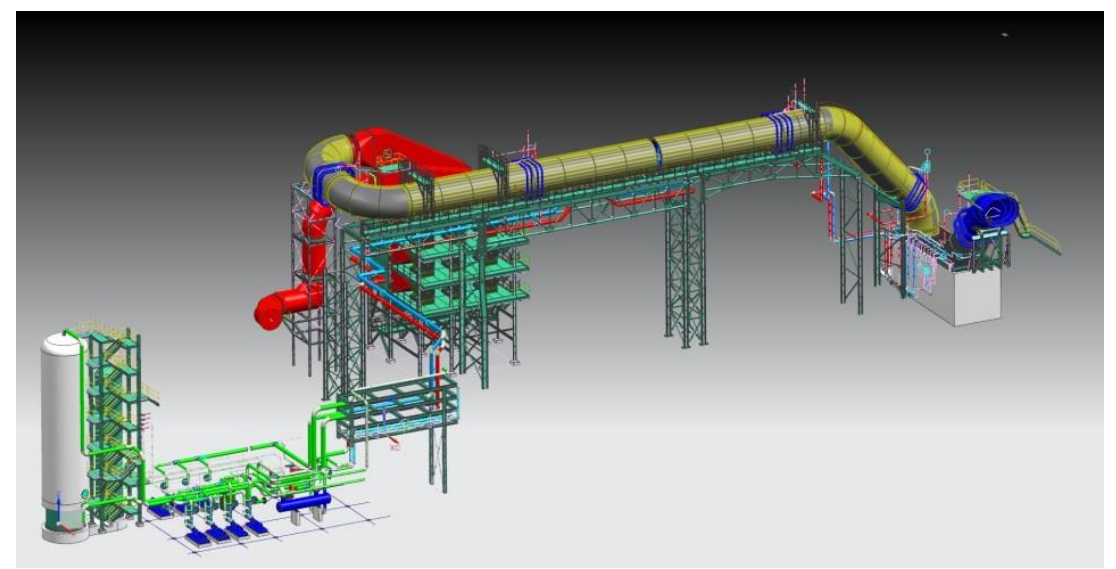

Figure 8: Waste heat recovery system with district heating applications

Besides internal or external heat utilization electric power generation can be an attractive option depending on the price of electricity. Especially considering various heat sources within the steel plant (e.g.: electric arc furnace, reheating furnace, etc.) these sources can be bundled for one combined power generation unit and therefore increase economic feasibility.

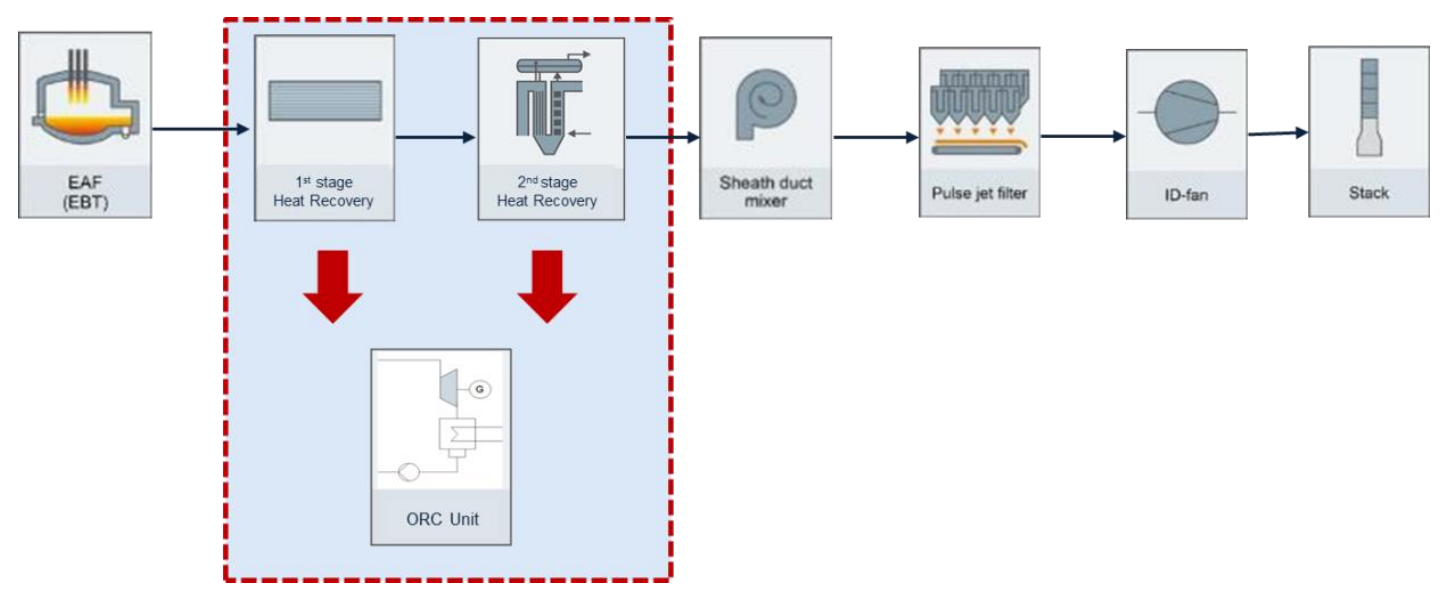

Figure 9: Waste heat recovery system with electric power generation

A simple and reliable solution for a power generation unit is an organic Rankine cycle (ORC) unit instead of steam turbine power block. ORC is a proven technology and ORC units are widely used in renewables and distributed power since the '70s. Typical ORC size ranges between few hundred kW electric up to $15 \mathrm{MW}$ and above. In the ORC process, designed as a closed loop, the organic working medium is preheated in a regenerator and in a pre-heater, then vaporized through heat exchange with the hot source (heat carrier or exhaust gas). The organic vapour is expanded in a turbine that drives an electric generator converting mechanical into electric power. Leaving the turbine, the organic working medium (still in the vapour phase) passes through the regenerator that is used to pre-heat the organic liquid before vaporizing, therefore, increasing the electric efficiency through internal heat recovery. 
The organic vapour then condenses and delivers heat to the cooling water circuit or directly to ambient air through air-condenser. After the condensation, the working medium is brought back to the pressure level required (for turbine operation) by the working fluid pump and then preheated by internal heat exchange in the regenerator. Mainly the following advantages can be recognized for ORC based heat recovery systems:

- $\quad$ Totally automatic system, no need of supervision personnel: ORC does not need supervision personnel in normal operating condition nor in shut down procedure. No additional personnel is needed

- $\quad$ Flexible operation in a wide range of thermal power loads: ORC module has a high level of automation and it is designed to automatically adjust itself to the actual operating conditions: variations on exhaust gas temperatures and flows will not affect the functionality of the system, but just the power output

- $\quad$ High efficiency even at partial load

- $\quad$ Long life with no major overhaul

- $\quad$ Minimum maintenance requirements: ORC units are remotely monitored and require minimal yearly maintenance activities.

- $\quad$ Possible configuration with no water consumption

\subsection{Waste Heat Recovery from Sinter Shaft Cooler}

The innovative sinter shaft cooler process is not only highly energy-efficient but also more environmentally friendly than any conventional sinter cooler today. The design allows the utilization of the total heat capacity from the hot sinter. The cooling air moves in countercurrent flow through the sinter during its descent through the shaft. With this approach, the air temperature leaving the shaft is maximized and efficiently applied for the generation of steam or electricity in downstream process steps, or used for the preheating and drying of materials or media used in the steelworks.

Compared to conventional sinter coolers, the sinter shaft cooler features lower specific investment and production costs, reduced energy consumption for sinter cooling, higher throughput and reduced dust and $\mathrm{CO} 2$ emissions due to a closed cooler shaft system.

\section{a. Status Quo Cross-flow Circular cooler}

The sinter is discharged from the sinter machine with a medium temperature in the range of $400{ }^{\circ} \mathrm{C}$ to $800{ }^{\circ} \mathrm{C}$, depending on the sinter process and raw materials. For the downstream processes the hot sinter should be cooled to less than $100{ }^{\circ} \mathrm{C}$. All applied cooler types (straight, circular) are based on the cross flow principle. Therefore, the bottom layers of the sinter bed are cooled faster than the upper layers, resulting in an unequal effective cooling time along the height of the sinter bed.

\section{b. Counter-current Shaft Cooler}

The shaft cooler follows the counter-current flow principle, meaning the cooling air flows in opposite direction to the sinter material flow. 


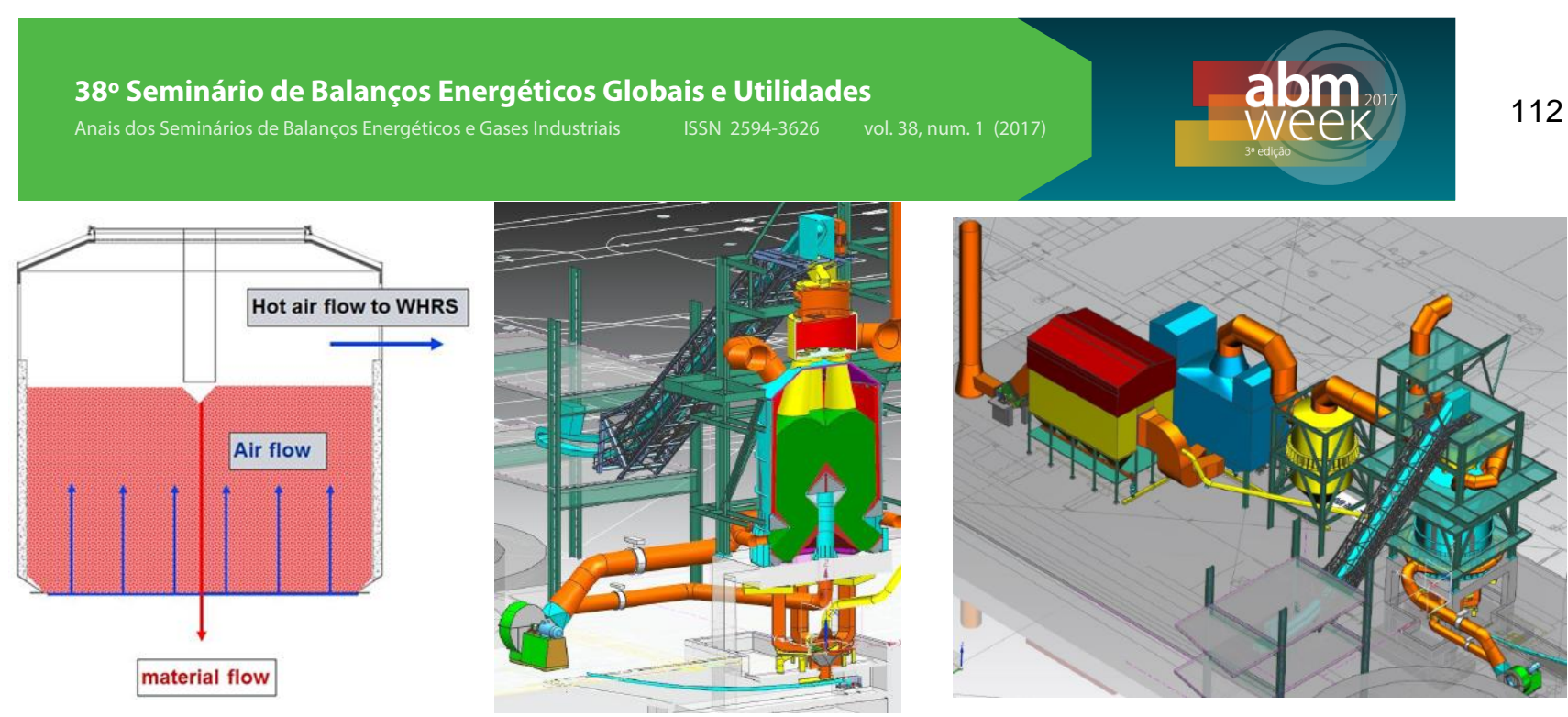

Figure 10: Shaft Cooler - left cooling principle, middle shaft cooler design, right shaft cooler system incl. WHR and de-dusting

The same effective cooling time for the whole material (irrespective of the position) and therefore an effective heat transfer from the material to the air is obtained. This leads to a maximized hot off-air temperature. It was observed that the temperature of the off-air is only slightly below the sinter charging temperature and nearly all of the heat is transferred to the air. The high off-gas temperature allows an efficient waste heat recovery.

\section{c. Comparing Circular Cooler and Shaft cooler}

Due to the fact, that for a circular cooler the temperature of the off-gas decreases along the circular sinter travel, only about one third of the exiting air amount can be used for heat recovery. The other part of the off-gas flow is too cold to make energy recovery feasible. The shaft cooler has several advantages. The temperature of the exiting air is by far higher, constant and thus all of the exiting air can be used for energy recovery. Another advantage is the much lower volume for the cooling air which requires only about one third of that for the circular cooler. Since all of the exiting air is used for steam production, diffusive emission is nearly decreased to zero.

Challenges for the development were to ensure a homogenous flow of sinter and air through the cooling bed. Segregation effects or different sink velocities of the solid material have to be avoided. Therefore, the feed charging to the shaft as well as the discharging are crucial factors. The charging equipment has to distribute the solid material to minimize segregation in lateral direction. The surface of the cooling bed has to be even (equal height) to ensure same pressure loss conditions in all positions. The discharging equipment has to prevent any core flow.

Figure 5 summarizes the main parameters for the two cooler types. The specific air demand of a circular cooler is about three times higher than for a shaft cooler. But only one third of the hot air from a circular cooler can be valorized for steam production. The shaft cooler allows full hot off-air utilization and therefore also supports the generation of power from the hot air which usually amounts to $36 \mathrm{~kW}$ per ton of sinter product. 
Table 3: Comparison between Shaft Cooler and Circular Cooler

\begin{tabular}{|l|l|l|}
\hline Specific air demand & \multicolumn{1}{|c|}{ Circular Cooler } & \multicolumn{1}{c|}{ Shaft Cooler } \\
\hline $\begin{array}{l}100 \% \\
\left(\sim 2000 \mathrm{Nm}^{3} / \mathrm{t}\right)\end{array}$ & $\begin{array}{l}\sim 30 \% \\
\left(\sim 580 \mathrm{Nm}^{3} / \mathrm{t}\right)\end{array}$ \\
\hline $\begin{array}{l}\text { Heat (air amount) usable } \\
\text { for WHR }\end{array}$ & $\sim 30 \%$ & $100 \%$ \\
\hline Residence Time & $\sim 79 \mathrm{~min}$ & $\sim 165 \mathrm{~min}$ \\
\hline $\begin{array}{l}\text { Bed Height } \\
\text { Dedusting Unit }\end{array}$ & $1,5 \mathrm{~m}$ & $6 \mathrm{~m}$ \\
\hline Power Generation & $100 \%$ & $<30 \%$ \\
\hline & $\begin{array}{l}14-25 \mathrm{~kW} / \mathrm{t} \text { sinter } \\
\text { product }\end{array}$ & $\sim 36 \mathrm{~kW} / \mathrm{t}$ sinter product \\
\hline
\end{tabular}

\section{Emission Control}

An effective long term emission control strategy can be a decisive factor as it is directly linked to governmental and authority permissions, the "green image" how a company is perceived by the market and its shareholders and the planning security to meet stricter environments regulations in the future. Solutions to minimize investment and operation cost for "end-of-pipe" solutions mainly by reducing waste gas amounts will be introduced, but also modular up-grade solutions to boost the performance in regard to emission levels and energy efficiency.

\subsection{Energy Saving Assistant}

In addition to process technologies to reduce energy consumption and turn waste heat into value, automation systems support to improve the energy consumption and process control for environmental plants. Above all secondary dedusting systems based on bag filter technology often suffer of non-optimized operation in terms of energy efficiency. The "Energy Saving Assistant" incorporates various measures based on advanced automation solutions. Figure 11 gives an overview on single automation improvements for an integrated steel plant.

Dynamic suction control helps to increase suction efficiency and reduce energy consumption. Typically, only single hoods of secondary dedusting system are evacuated depending on a certain control matrix due to the limited size of the filter plant. Usually these control values are mainly set manually in a matrix. Whereas applying the dynamic suction control, the pressure profile in the duct system is calculated online, based on the operating condition of the plant. Based on the pressure profile two results are calculated: the opening percentage for every suction damper and the set point for pressure control loop for ID fan. Thus, no additional measurements are required. Apart from the damper positions, the algorithm controls also the variable speed of the (respectively the fan load damper position) and leads to an optimized energy consumption. Typically the implementation of an advanced damper control systems can result in an energy saving of up to $20 \%$. This control strategy has been successfully implemented at Buderus Edelstahl in Wetzlar, Germany, a plant with one EAF and another 19 different evacuation sources. 


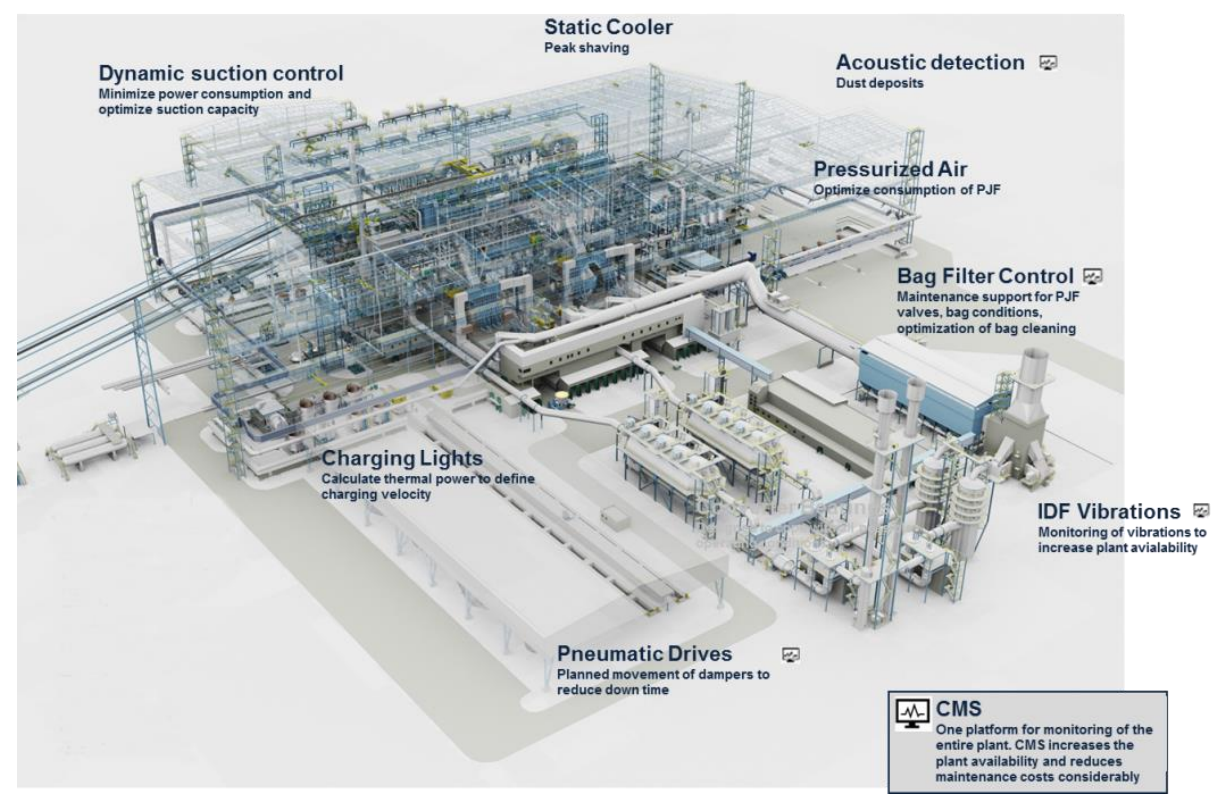

Figure 11: Typical drawing of a plant dedusting system including automation packages for energy saving

Furthermore, a standard bag filter operates without any dynamic energy optimization, based on fixed cleaning cycles where the cleaning valves purge compressed air into the filter bags by means of jet pulse technology. A malfunction of a cleaning valve can only be detected manually through acoustic checks. These are both time consuming and cost intensive. Furthermore, a fixed amount of compressed air for filter bag cleaning is used for each cleaning valve. Most of the cost-intensive compressed air is wasted, because the cycle time cannot be adjusted automatically based on the actual process parameters. To activate a cleaning valve, electromechanical relays switch on the power for the solenoid valve. An optimized bag filter control is the major precondition for cost reductions. Using a differential pressure measurement between bag filter inlet and outlet, and the actual volume gas flow, an optimal cleaning cycle mode is automatically selected by the Bag Filter Control unit. A fast and reliable electronic module, which additionally features selfmonitoring functions, controls the cleaning valves. The duration of the open time for each cleaning valve can be adjusted and in combination with diaphragm valves a reduction of $30 \%$ in compressed air can be achieved. An additional feature of the Bag Filter Control unit is the built in condition monitoring featuring the continuous supervision of each cleaning valve which generates a warning at the $\mathrm{HMI}$ in case a malfunction is detected at one of the cleaning valves.

With Acoustic Plant Monitoring a new system with high potential is introduced. The system checks the noise frequency band of the surrounding area. Once the system detects an acoustic situation out of its normal operating limits the soundscape is going to be recorded for some seconds. A following detailed analysis of this recorded sound stream leads to a statement whether the observed equipment works at its proper conditions or not. The system is adaptable for nearly every field of application with continuous diagnostics for production and maintenance support (e.g. cleaning valves, dust transport systems, dust deposits, etc.). Records provide reports over the whole equipment utilization time and can be easily installed and implemented without disruption of the ongoing production. 


\subsection{Milestone for Competitive Zero Emission Dedusting Systems - The Kappa ZERON® Filter}

Kappa Zeron® is an IP protected fully integrated filter house in a unique massive concrete panel design, which feature absolute emission tightness (sound and particulate emission).

This innovative design and construction allows a compact footprint, close to zero particulate emissions, lowest pressure loss and lowest sound emission levels.

\section{Absolute emission tight housing}

Concrete panels can be produced in 10-times larger dimensions compared to steel sheet based panels. Therefore the sealing edge length is essentially reduced. The flexible sealing material and the unique clamping system results in tightness of the housing unattained so far. Any dust leakage to the clean gas side can be ensured. There are no stiffeners in the bag housing required; thus avoiding scrubbing of the bags when touching any stiffeners.

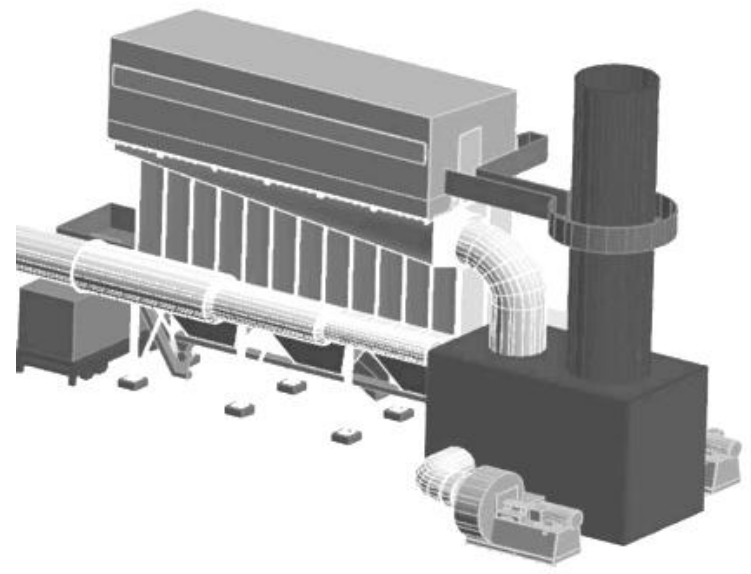

Figure 12: Standard Bag-filter Design

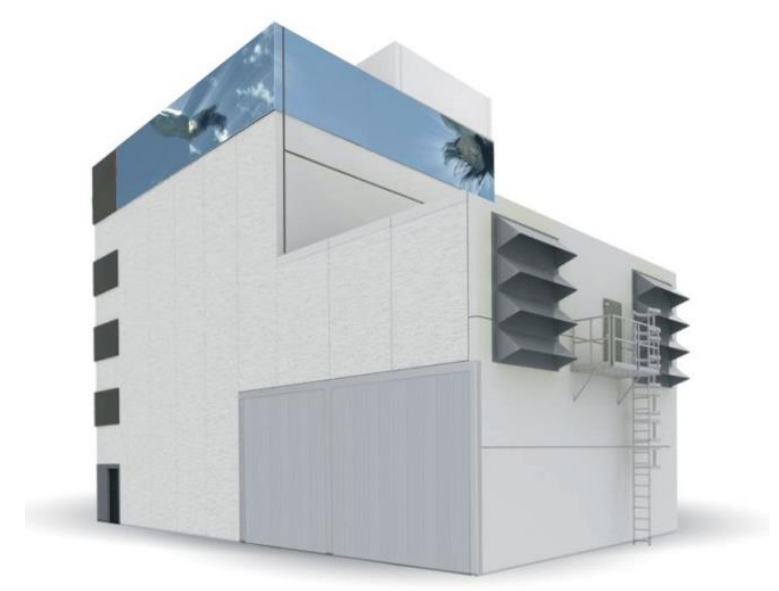

Zeron Design

\section{Lowest Sound Emissions}

The massive concrete panels achieve a substantial sound level reduction of $57 \mathrm{~dB}$. Filter penthouse and fan house are fabricated from such concrete panels also cleaning pulse noise and fan noise are effectively reduced to a minimum. There is no requirement for any additional sound or thermal insulation cladding as used for steel panel construction. The special design of the gas inlet and outlet features low gas velocities which result in a moderate flow noise.

\section{Minimum Pressure Loss}

The intelligent construction, with an integrated design of all components within a single building, features the lowest ever achieved pressure loss for a fabric filter unit and thus lowest energy consumption of the fan, which is responsible for $85-90 \%$ of the opex of a filter unit.

\section{Maximum Flexibility - Modular Construction}

The modular filter design allows for later extension of the filter area if required in the future. The concrete panel construction can be dismantled and reinstalled without damage of the filter elements. 

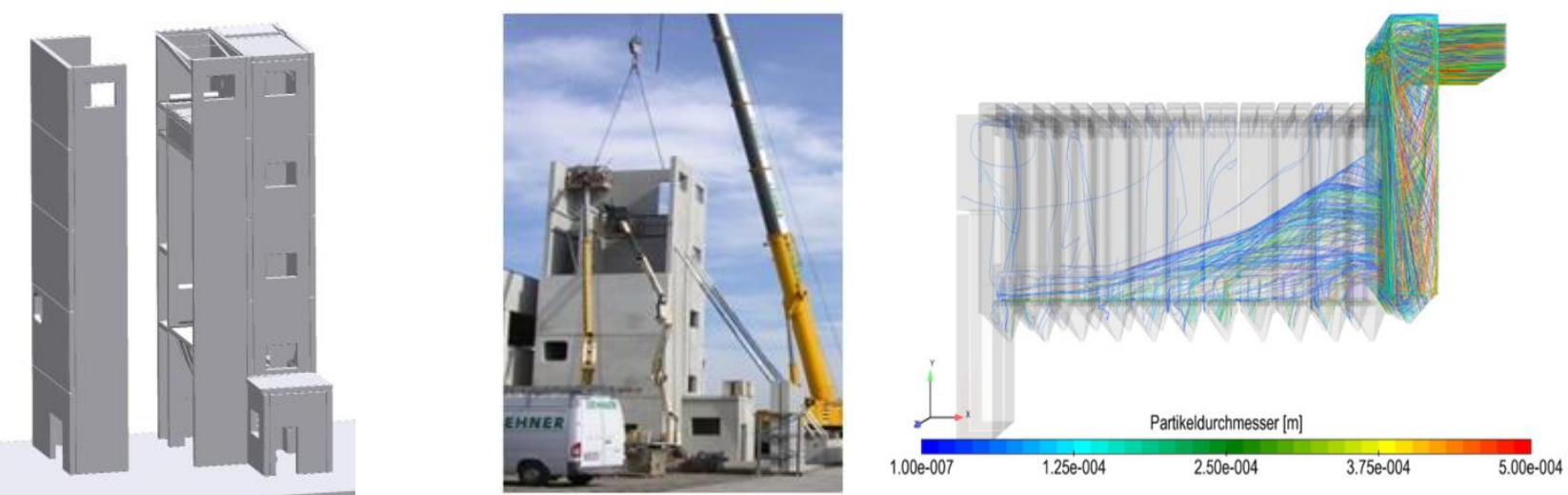

Figure 13: Modular system (left) - Filter erection (middle) - Flow optimized design (right)

\section{Robust and Weather Resistant}

The massive concrete elements ensure protection for explosions, fire, corrosion and weather (wind, snow loads and earthquake. Pressure resistance up to $+/-15.000 \mathrm{~Pa}$.

\section{Fabrication and Erection}

The concrete panel plates can be locally casted. The big dimensions of these panels allow much faster erection of the whole filter system. Even the weight of the panels is high foundation work is limited due to the area loads instead of point loads in case of a steel structure support.
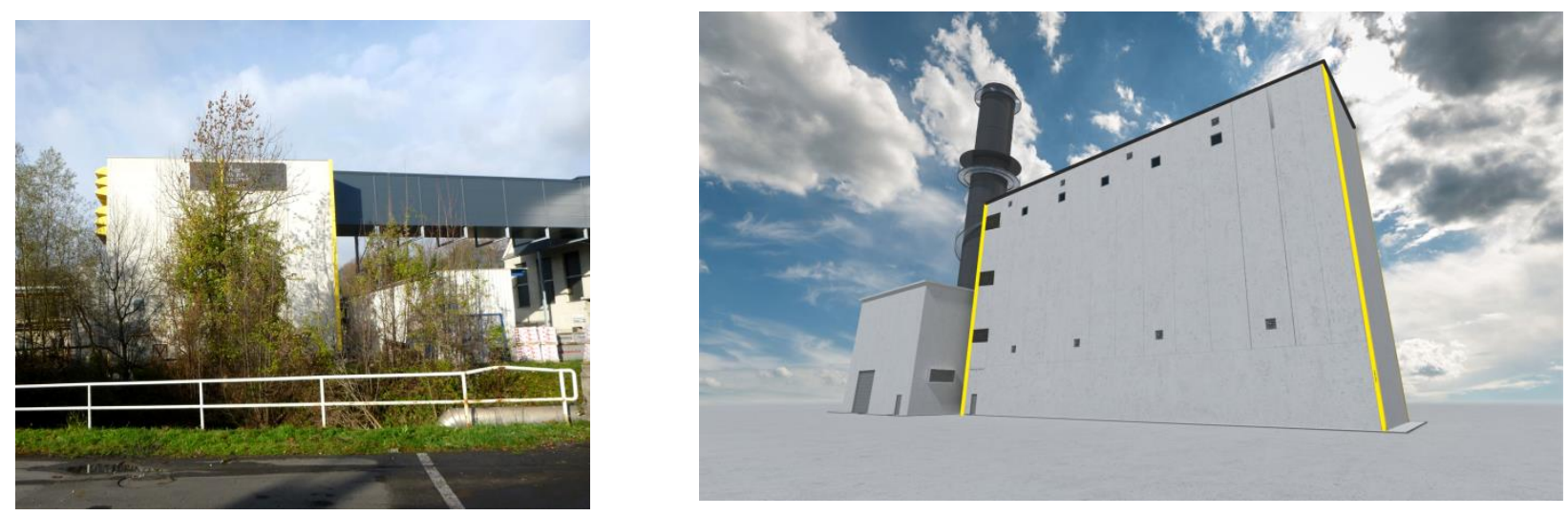

Figure 14: Zeron project examples - 260.000 Am³/h (left) - 1.300.000 Am³/h (right)

\section{CONCLUSION}

The actual difficult global market situation arising from oversupply of steel and resulting inadequate product margins, unpredictable raw material and energy prices, political and macro-economic discussions about climate change and carbon footprint reduction of the heavy industry as well as globally becoming stricter environmental regulations related to emissions levels, water scarcity and pressure towards a zero waste production requires immediate action. 
Consequently main focus to manage these challenges is to implement innovative technologies and measures to optimize production costs while maintaining the environmental issues to stay ahead competition.

Technologies that allow for high raw material flexibility are a decisive factor to adapt quickly to changing market conditions.

Even the steel sector was continuously implementing various measures to optimize the specific consumption figures, improving the reliability of equipment, working conditions and plant safety there is still a huge potential to move this industry towards a sustainable steel production.

Leap-frog innovations like the Jet Technology, by-product valorisation, heat recovery from various process steps, and advanced control and automation systems leave a lot of room to achieve the next level of a sustainable steel industry. 